\title{
Measuring and Modifying Interface Properties of PVA Fibers IN ECC MATRIX
}

\author{
By Carl Redon, ${ }^{1}$ Victor C. Li, ${ }^{2}$ Fellow, ASCE, Cynthia Wu, ${ }^{3}$ Hideki Hoshiro, ${ }^{4}$ Tadashi Saito, \\ and Atsuhisa Ogawa ${ }^{6}$
}

\begin{abstract}
A single fiber pullout test was used in this study to measure the bond properties of polyvinyl alcohol fibers that are available at various diameters in a mortar matrix. Despite short fiber embedment lengths, the small diameter fibers ruptured during the pullout tests. However, it is shown that even if full fiber pullout is not achieved, it is still possible to determine a chemical debonding energy, $G_{d}$, and an initial interfacial frictional bond strength, $\tau_{0}$. Despite high $G_{d}$ values, the fibers did not rupture during the fiber chemical debonding process, but during fiber pull-out, a strong slip-hardening effect, characterized by the high values of the sliphardening coefficient, $\beta$, induced severe abrasion damage visible under scanning electron microscope on the fiber surface. As a consequence, when the fiber apparent tensile strength was exceeded, fibers ruptured by delamination. Finally, an attempt was made to lower the values of the bond properties to minimize fiber rupture during pullout. This goal was partially achieved by applying an oil coating on the hydrophilic polyvinyl alcohol fiber surface to reduce any strong fiber/mortar interaction.
\end{abstract}

\section{INTRODUCTION}

A method to directly assess fiber/mortar interfacial bond properties is to pull a single fiber out of its surrounding matrix. The bond properties are mainly described through the notions of chemical debonding energy, $G_{d}$, of frictional bond strength at the onset of fiber slippage, $\tau_{0}$, and of slip-hardening or slipsoftening coefficient, $\beta$ (Lin and Li 1997; Lin et al. 1999). A variety of fiber pull-out models (Gao 1987; Hsueh 1990; Stang and Shah 1990) are available to interpret the experimental data into interface bond properties. In the present paper, bond properties of polyvinyl alcohol (PVA) fibers in a mortar matrix were investigated with the simplified model of Lin et al. (1999), which includes all of the above three bond properties.

Generally fiber pullout rather than rupture confers a larger ductility to the fiber reinforced composites (Cooper and Kelly 1970; Lin and $\mathrm{Li}$ 1997, Li et al. 1997). It is desirable to have composites that exhibit strain-hardening behavior achieved through multiple cracking of the reinforced matrix (Naaman and Reinhardt 1996). Making use of nonlinear fracture mechanics concepts, mortar composites named Engineered Cementitious Composites (ECC) have been designed to satisfy this objective ( $\mathrm{Li}$ and $\mathrm{Wu} \mathrm{1992;} \mathrm{Li}$ et al. 1995). For that, it is necessary to satisfy two conditions: (1) the ultimate composite strength has to be higher than its first crack strength; and (2) the complementary energy of the composite has to exceed the matrix crack tip fracture toughness (Marshall and Cox 1988; Li et al. 1996a)

${ }^{1}$ Res. Fellow, ACE-MRL, Dept. of Civ. and Envir. Engrg., Univ. of Michigan, Ann Arbor, MI 48109-2125.

${ }^{2}$ Prof. and Dir., ACE-MRL, Dept. of Civ. and Envir. Engrg., Univ. of Michigan, Ann Arbror, MI (corresponding author). E-mail: vcli@engin. umich.edu

${ }^{3}$ Grad. Student, ACE-MRL, Dept. of Civ. and Envir. Engrg., Univ. of Michigan, Ann Arbor, MI

${ }^{4}$ Engr., Industrial Goods Development Dept., Kuraray Co., Ltd., Okayama Plant, 1-2-1 Kaigandori, Okayama City, Okayama 702-8045, Japan.

${ }^{5}$ Engr., Industrial Goods Development Dept., Kuraray Co., Ltd., Okayama Plant, 1-2-1 Kaigandori, Okayama City, Okayama 702-8045, Japan.

${ }^{6}$ Engr., Industrial Goods Development Dept., Kuraray Co., Ltd., Okayama Plant, 1-2-1 Kaigandori, Okayama City, Okayama 702-8045, Japan.

Note. Associate Editor: Nemkumar Banthia. Discussion open until May 1, 2002. To extend the closing date one month, a written request must be filed with the ASCE Manager of Journals. The manuscript for this paper was submitted for review and possible publication on October 18, 1999; revised November 28, 2000. This paper is part of the Journal of Materials in Civil Engineering, Vol. 13, No. 6, November/December, 2001. (C)ASCE, ISSN 0899-1561/01/0006-0399-0406/\$8.00 + \$.50 per page. Paper No. 22094.
PVA fibers are hydrophilic. They strongly bond to the surrounding cementitious matrix. This tends to limit the multiple cracking effect and leads to lower strain hardening profiles for the composite. Reducing the chemical debonding energy enhances the complementary energy (Li et al. 1997) by minimizing premature fiber breakage during the fiber/matrix interface debonding process, prior to fiber slippage. Lowering within certain limits the interfacial frictional bond strength at the onset of fiber slippage can also facilitate fiber pullout. For some polymer fibers, such as PE fibers and PP fibers, it has been shown with a single fiber pullout test that increasing the interface friction during fiber slippage induced a slip hardening behavior (Wu and Li 1997). This can lead to improved strain hardening at the composite level (Li et al. 1996b). However, the slip-hardening should not be so high that it causes fiber rupture. If necessary, a simple way to reduce overly strong interfacial bonding would be to adjust the bond properties by coating the fiber with an oiling agent.

The objective of this study is to determine appropriate interfacial parametric values for use in micromechanical models of ECC composites, as well as extracting knowledge on fundamental processes governing the bridging behavior of PVA fibers in ECC composites. In the following paragraphs: the fibers tested and the matrix used are presented; the experimental procedure is described; definitions of three bond parameters $G_{d}, \tau_{0}$, and $\beta$ are given; and the method of their determination from single fiber pullout tests data are briefly reviewed. Pullout test results and SEM observations of PVA fibers and the effects of oil coating on bond properties are finally presented and discussed.

\section{MATERIALS AND TESTING TECHNIQUES}

The characteristics of the PVA fibers are listed in Table 1. Two types of fibers were investigated: (1) Fiber A had a small diameter, about $0.044 \mathrm{~mm}$; and (2) the diameter of Fiber B was about $0.700 \mathrm{~mm}$. Although both are PVA fibers with the same chemical structure, the manufacturing processes are dif-

TABLE 1. Dimensional and Mechanical Characteristics of the PVA Fibers Investigated

\begin{tabular}{lcccc}
\hline \hline & & Tensile & & Young's \\
& Diameter & strength & Elongation & $\begin{array}{c}\text { modulus } \\
d_{f}\end{array}$ \\
Fiber & $(\mathrm{mm})$ & $(\mathrm{MPa})$ & $\sigma_{t}$ & $E_{f}$ \\
\hline A & 0.044 & 1,640 & 5.3 & $(\mathrm{GPa})$ \\
$\mathrm{B}$ & 0.700 & 816 & 11 & 41.1 \\
\hline \hline
\end{tabular}


ferent, leading to differences in surface texture. Fiber $\mathrm{A}$ is processed via a so-called solvent wet gel spinning method that should provide a smooth fiber surface. A dry spinning method was used to process Fiber B and its surface is expected to be rougher, exhibiting many creases. The fibers were embedded in an ECC matrix whose composition has the following weight ratios: cement:water:sand:superplasticizer (SP):methyl cellulose (MC): antidefoamer $(\mathrm{AF})=1: 0.30: 1: 0.03: 0.0005: 0.0005$. The cement is an ordinary Portland cement Type 1; the sand is a fine silica fine sand with size range from $0-0.3 \mathrm{~mm}$. The $\mathrm{SP}$ is a polymelamine; the viscosity agent is an MC; $\mathrm{AF}$ is added to the ECC mix.

Fig. 1 shows how the fiber pullout specimens were made. The Fiber A embedment length, $l_{e}$, was chosen close to 0.8 $\mathrm{mm}$ to try to ensure full debonding. To obtain such a small length, the Fiber A pullout specimens were cut from thin cast EEC plates in which continuous PVA fibers were embedded (Katz and Li 1996). For Fiber B, once the embedment length was adjusted to $5 \mathrm{~mm}$, the pullout specimens were directly cast. Both sets of specimens were wrapped in plastic sheets after demolding until they were tested at 14 days.

The pullout tests were conducted at a speed of $0.02 \mathrm{~mm} / \mathrm{s}$ on an MTS 810 (USA) testing machine (Fig. 2). A 10-N Sensotec (USA) load cell with a $2-\mathrm{N}$ range was used to measure the pullout forces for Fiber A. Within this 2-N range, the error on the load measurement was lower than $1.25 \%$. The pullout load for Fiber B was measured with a 120-N MTS (USA) load cell. Above $10 \mathrm{~N}$ the error on the load measurement was lower than $5 \%$. The displacement, $S$, or $x$-axis of the pullout curves, is given by the displacement of the actuator ( $\pm 80 \mathrm{~mm}$ stroke). For both Fibers A and B, the elastic stretching of the $1-\mathrm{mm}$ fiber-free length was considered negligible (less than $0.1 \%$ of the fiber-free length at peak load $P_{a}$ ). It has not been subtracted from the $\mathrm{S}$ values of the displacement. For $\tau_{0}$ and $G_{d}$, they depend only on the accuracy of the load value but not on that of displacement. For $\beta$ determination, the measured displacements are on the order of 0.1 to $1 \mathrm{~mm}$, so that the influence of elastic stretching of the fiber on the accuracy of $\beta$ is expected to be small.

\section{PROFILE OF THE SINGLE FIBER PULLOUT CURVE AND DEFINITION OF BOND PARAMETERS}

The general profile of a single fiber pullout curve can be decomposed into three major regimes (Fig. 3). Initially, a stable fiber debonding process occurs along the fiber/matrix interface [Fig. 3(a)]. The load resisted by the fiber is increasing up to $P_{a}$. The fiber embedded end, $l=l_{e}$, does not move. The debond length, $l_{d}$, increases towards $l_{d}=l_{e}$. The displacements correspond only to the elastic stretching of the debonded fiber segment and of the fiber-free length.

Then the load decreases from $P_{a}$ to $P_{b}$. If the load drop is significant, it reveals that the chemical bond between the fiber and the matrix was broken. In the case of PVA fibers, the $P_{a}$

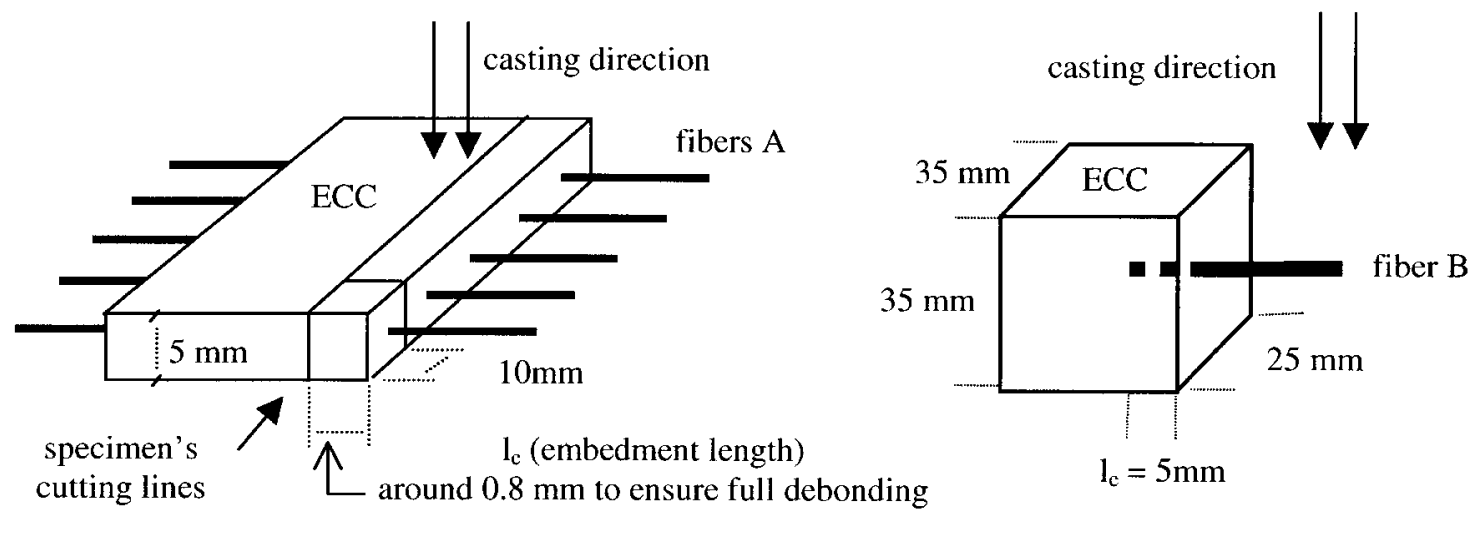

(a)

(b)

FIG. 1. Pull-Out Specimens: (a) PVA Fibers A; (b) Fibers B

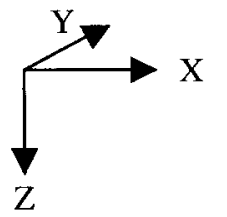

Fiber free length $=1 \mathrm{~mm}$

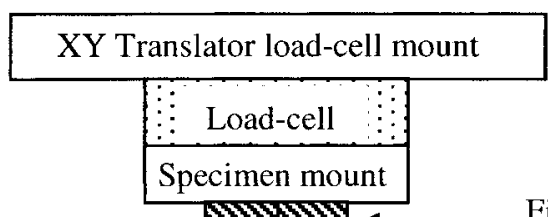

Fiber A : specimen glued

Fiber B : specimen held by grips

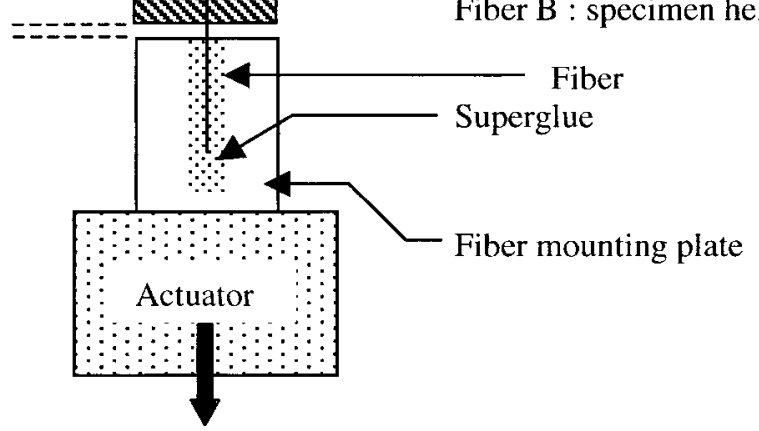

FIG. 2. Scheme of the Single Fiber Pullout Experimental Set-Up 


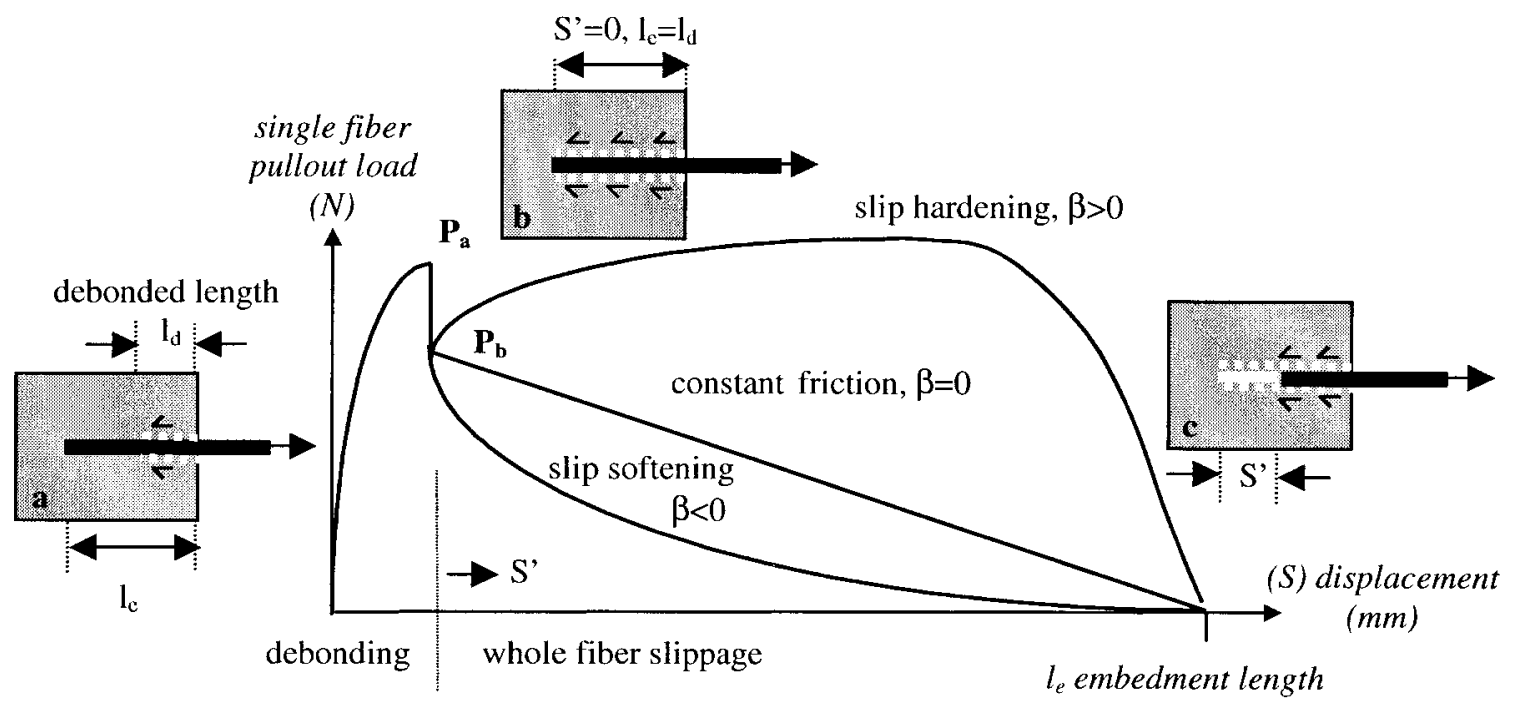

FIG. 3. General Profile of a Single Fiber Pullout Curve

to $P_{b}$ load drop is distinct and occurs very suddenly (Fig. 4). This means that debonding at the interface is governed by a fracture criterion rather than by a strength criterion (Leung and Li 1990; Li and Stang 1997). The unstable interface fracture could be heard when pullout tests were conducted on large Fibers B. The chemical debonding energy value, $G_{d}$, is calculated from the $P_{a}$ to $P_{b}$ difference, shown in (1)

$$
G_{d}=\frac{2\left(P_{a}-P_{b}\right)^{2}}{\pi^{2} E_{f} d_{f}^{3}}
$$

where $E_{f}=$ fiber axial Young's modulus; and $d_{f}=$ fiber diameter (Li et al. 1998).

In the case of nonchemically bonded fibers, such as steel or polyethylene fibers, $P_{a}$ would be close or equal to $P_{b}$. At point $P_{b}$, the embedded fiber end is just debonded [Fig. 3(b)]. From the $P_{b}$ value, one calculates the frictional bond strength $\tau_{0}$ at the onset of fiber slippage $\left(S^{\prime}=0\right.$ at $\left.P_{b}\right)$

$$
\tau_{0}=\frac{P_{b}}{\pi d_{f} l_{e}}
$$

Finally, in the slippage regime, the fiber load is resisted by frictional forces [Fig. 3(c)]. The fiber can undergo sliding with either slip hardening, constant friction or slip-softening effect, characterized by the coefficient $\beta$, which is, respectively, positive, zero or negative (Lin and Li 1997). Slip-hardening occurs often with polymer fibers. Because they are less hard than the surrounding matrix, they are damaged and a jamming effect can take place inside the matrix. This leads to an increasing load resisting fiber pullout. This phenomenon can be very beneficial as long as the fiber tensile strength is not exceeded. Conversely, constant friction or slip-softening are often observed when the fiber hardness is higher than that of the surrounding matrix. The $\beta$ value is calculated from the initial $\left(S^{\prime}\right.$ approaching 0 ) slope of the $P$ versus $S^{\prime}$ curve and using

$$
\beta=\left(d_{f} / l_{f}\right)\left[\left.\left(1 / \tau_{0} \pi d_{f}\right)\left(\Delta P / \Delta S^{\prime}\right)\right|_{S^{\prime} \rightarrow 0}+1\right]
$$

Eq. 3 is based on assuming a linear slip dependence of the friction $\tau$, so that

$$
\tau=\tau_{0}\left(1+\beta \frac{S^{\prime}}{d_{f}}\right)
$$

and therefore, ignoring (Fig. 4) second-order terms in $S^{\prime 2}$ suitable for small $S^{\prime}$, the pullout force $P$ can be expressed in terms of slip $S^{\prime}$

$$
P=\tau_{0} \pi d_{f}\left[l_{e}+S\left(\beta \frac{l_{e}}{d_{f}}-1\right)\right]
$$

\section{ABRASION AND RUPTURE OF POLYVINYL ALCOHOL (PVA) FIBERS DURING SLIPPAGE}

Calculating the $\tau_{0}$ value from (2) implies that the fiber must be fully debonded. This is obviously achieved when the last slippage distance recorded on the single fiber pullout curve corresponds to the original embedment length, $l_{e}$. However, the type of curve shown in Fig. 4(a) has often been observed for the Fibers A.

Fiber A ruptured before the full pullout length, at least equal to $l_{e}$, had been reached. A comparison indicates that the shape of a pullout curve for a large Fiber B was similar prior to the second peak. Moreover, complete fiber pullout was achieved for Fiber B [Fig. 4(b)]. However, in case of Fiber A, SEM observation of the back end of a pullout specimen provides absolute evidence of the complete fiber debonding in the case of a pullout profile such as shown in Fig. 4(a). Indeed, the fiber embedded end is not visible any more at the back surface of the specimen but has slipped inside the fiber tunnel in the ECC matrix (Fig. 5). After verifying this, it is correct to ascribe $P_{b}$ to the endpoint of the first sudden load drop in the pullout curves and to calculate a $\tau_{0}$ value even though the fibers eventually rupture.

The second rising portion of the pullout curve, prior to the second peak, corresponds to a slip-hardening effect. On another series of pure cement pullout specimens, the matrix surrounding the fiber has been dissolved in hydrochloric $(\mathrm{HCl})$ acid at various steps of the pullout displacement to observe the changes of the embedded surface of the large diameter Fiber B (Fig. 6). Up to the $P_{b}$ point, no changes are visible [Fig. 6, Points A and B); then abrasion damage gradually takes place. Fiber delamination occurs as layers, or fibrils, of PVA material are peeled off backwards toward the fiber embedded end (Fig. 6, Points $\mathrm{C}$ and D). The phenomenon contributing to the slip-hardening effect continues until most of the fiber end is peeled off, when force levels close to a maximum are recorded (Fig. 6, Point E). At later stages of the pullout test, the fiber embedded end appears thinned (Fig. 6, Point F). Valleys of missing PVA are now visible on the fiber surface. Fiber $\mathrm{B}$, observed after being fully pulled out of an ECC mortar also exhibits an embedded end narrower than the original $0.7-\mathrm{mm}$ diameter and also has a cut cone shape [Fig. 7(a)]. Abrasion damage affected only a peripheral zone of the fiber, leaving its core intact and allowing further fiber sliding at lower pull- 


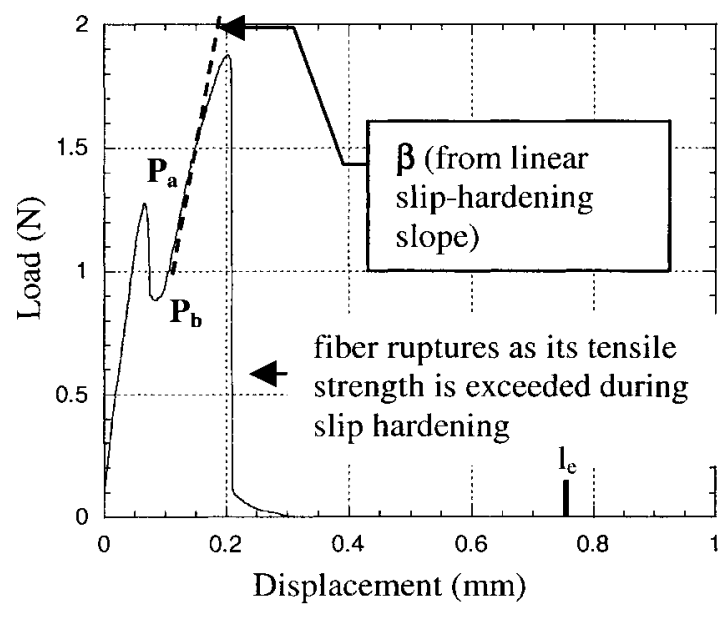

(a)

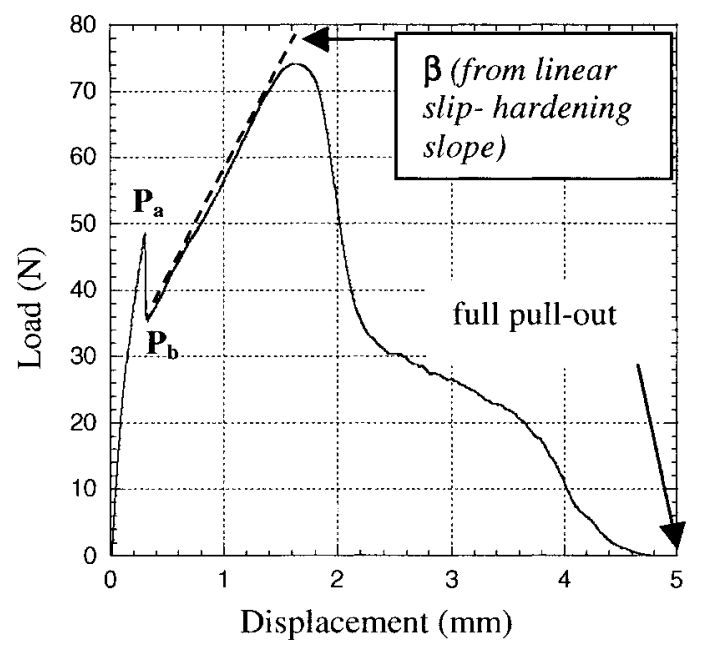

(b)

FIG. 4. Typical Pullout Curve: (a) Fiber A $\left(l_{e}=0.749 \mathrm{~mm}\right)$; (b) Fiber $\mathrm{B}\left(l_{e}=5 \mathrm{~mm}\right)$

out load levels. Indeed, most of the large Fibers B were fully pulled out. The gradual load decrease during the last steps of the pullout curve is the result of two phenomena. The fiber force must decrease as the remaining embedment length decreases. In addition, the fiber/matrix interface friction likely decreases rapidly due to the reduced fiber diameter when delamination is completed. This second phenomenon may explain why the load decreases rapidly and also why the zero load level was often recorded before the 5-mm displacement, which corresponds to the original embedment length, had been reached. The highest stress values recorded during the sliphardening regime were about $30 \%$ of the Fiber B nominal tensile strength, which then could not lead to fiber rupture.

Conversely, most of small Fibers A ruptured during the sliphardening regime of a strength level about $60 \%$ of their nominal tensile strength. A notion of apparent tensile strength has been defined by Kanda and $\mathrm{Li}$ (1998) as being the rupture strength of the fiber with one of its ends embedded in a cementitious matrix. When the fiber is pulled out straight, with no inclining angle, Kanda and $\mathrm{Li}$ (1998) suggested that the decrease of the tensile strength of the fiber (from its nominal strength) was due to abrasion damage on the fiber surface. Fig. 7(b) provides evidence that the severe abrasion process affects not only the small fiber's periphery, but its whole diameter, leading to rupture by delamination through the fiber thickness.

\section{INTERFACIAL BOND PROPERTIES AND THE EFFECT OF OIL COATING}

From the above pullout curves and the SEM observations, it is now obvious that the PVA fibers have both strong chemical and frictional bonding in the ECC matrix. First, the chemical bond is important as a significant $P_{a}$ to $P_{b}$ load drop is evident in Figs. 4( $a$ and $b$ ). Then the slip-hardening effect also strongly resists complete fiber pullout. As suggested in the introduction, it would be desirable to lower $G_{d}$ to obtain PVAECC composites that exhibit higher complementary energy. It is also desirable to reduce the slip-hardening effect to avoid fiber rupture. To achieve these goals, an oil coating was applied to the fiber surface.

In the case of Fibers B, the oil coating reduces $P_{a}$ and $P_{b}$ values as well as the $P_{a}$ to $P_{b}$ difference on average, as illustrated by the comparison of Figs. 8(a and $\mathrm{b})$. In the nonoiled case, few of the Fibers B ruptured after a strong slip-hardening. But, with the oil coating, slip-hardening is almost nonexistent, resulting in a more-or-less linear load decay with displacement (almost constant friction, or $\beta \sim 0$ ) in the pullout branch [Fig. 8(b)].

In the case of small Fibers A, the effects of the oil coating are not so obvious when comparing Figs. $9(\mathrm{a}$ and $\mathrm{b})$. There is a trend indicating that $P_{a}$ and $P_{b}$ are also reduced due to the oil coating and an average tendency indicating a lower $P_{a}$ to $P_{b}$ difference. But the oiling agent had very little influence on the slip-hardening effect, and most of the fibers broke even if longer pullout displacements were recorded.

The measurement of bond properties for Fibers B and A, untreated and coated, are given, respectively, in Figs. 10 and 11. Particularly in the case of Fiber A, the $\tau_{0}$ and $G_{d}$ values

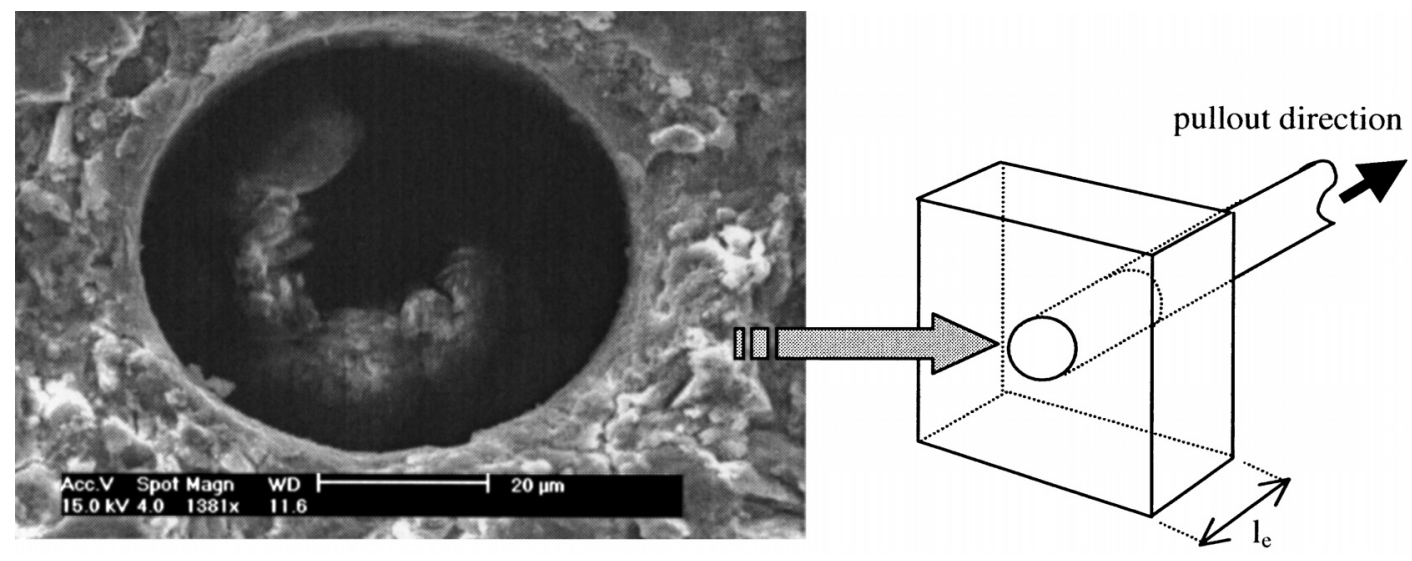

FIG. 5. SEM View of the Back End of the Pullout Specimen for Fiber A (The Fiber Embedded End Is Not Visible at Surface but inside Matrix Tunnel) 


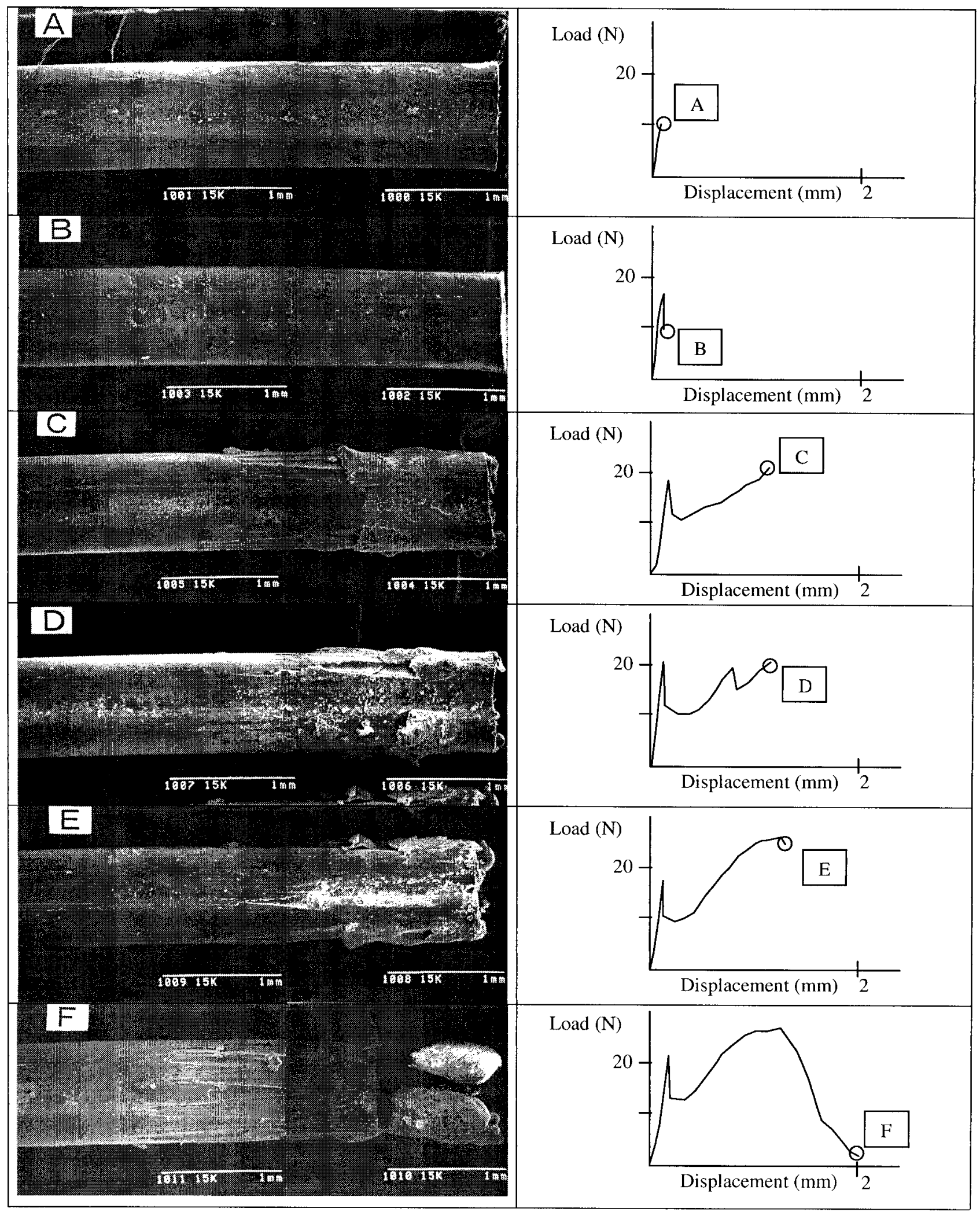

FIG. 6. Evolution of Abrasion Damage on Surface of Fiber B, Illustrated with SEM Pictures A to F, Corresponding, Respectively, to Events A to F of Pullout Curves Presented on Right Column

show significant scatters, as is typical of this type of measurements. But considering the overall data trend, it appears that both bond parameters $G_{d}$ and $\tau_{0}$ show reduced values when the oil coating was applied.

The average values of $\tau_{0}$ and $G_{d}$ have been calculated in the following manner: (1) all the $\tau_{0}$ and $G_{d}$ values obtained from each individual pullout test (data points on Figs. 10 and 11) were averaged; and (2) upper and lower limits were set at these averages $\pm 30 \%$. The averaged values reported in Table 2 correspond to the average of the values falling within these limits. $\beta$ values were much more consistent from one test to the other. Their direct average values are also summarized in Table 2. 


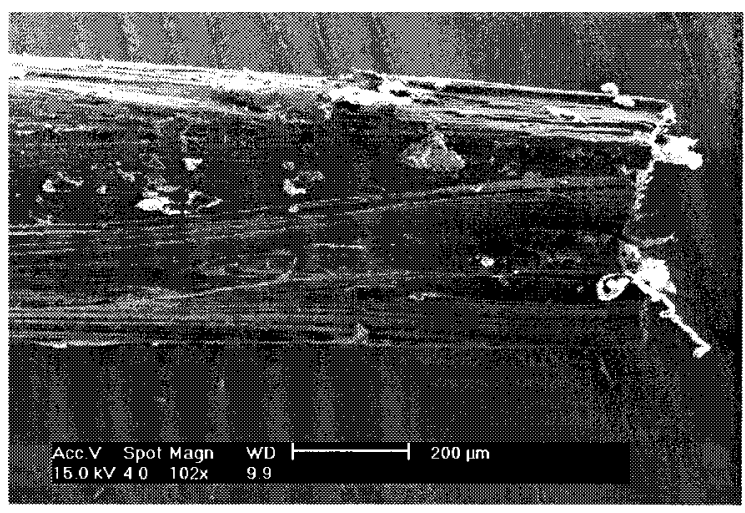

(a)

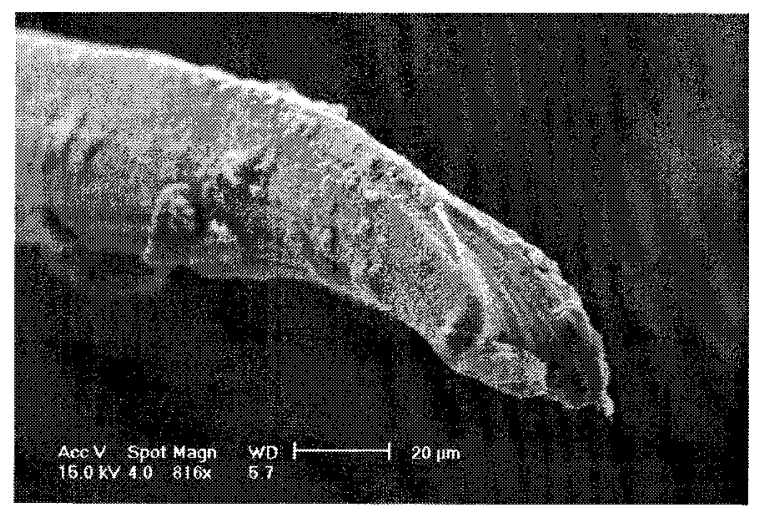

(b)

FIG. 7. (a) Pullout End of Fiber B Showing Removal by Abrasion of PVA Material; (b) Delaminated Ruptured End of Fiber A

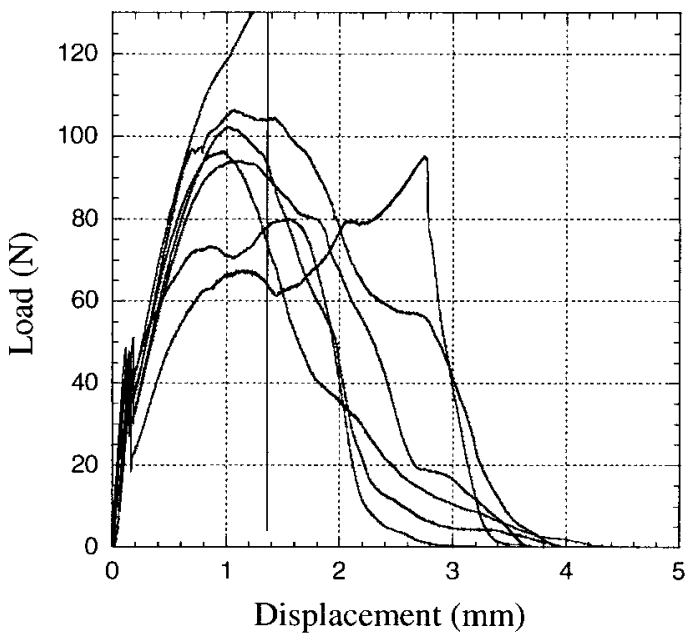

(a)

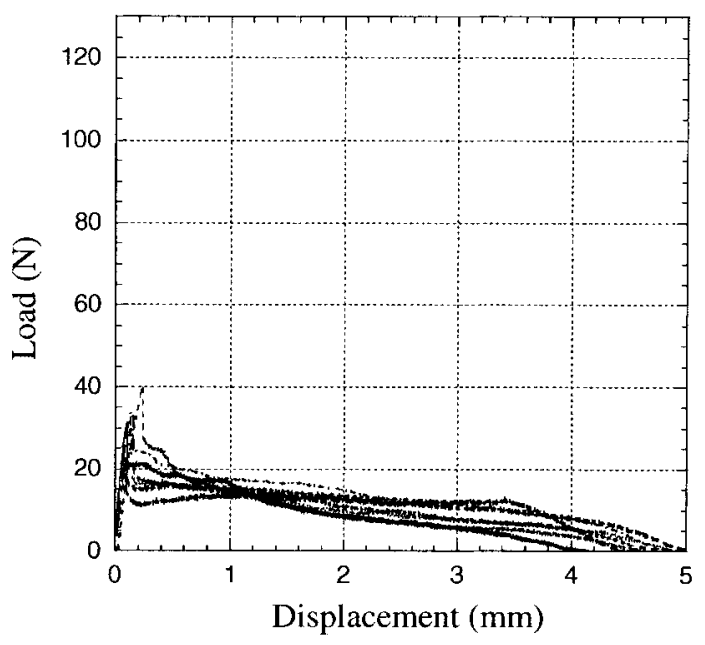

(b)

FIG. 8. Pullout Curves for Fibers B: (a) Nonoiled; (b) Oil Coated

Considering nonoiled fibers, $\tau_{0}$ values for Fiber B are close to $3 \mathrm{MPa}$, unexpectedly lower than for Fiber A around $5 \mathrm{MPa}$, which processed via a solvent wet gel spinning method should provide a smoother fiber surface. Conversely, it seems logical to measure a larger slip-hardening coefficient $\beta$, about 2.5 for Fiber B, which is expected to be rougher instead of 0.4 for Fiber A. Similarly, if $G_{d}$ values can be linked to roughness

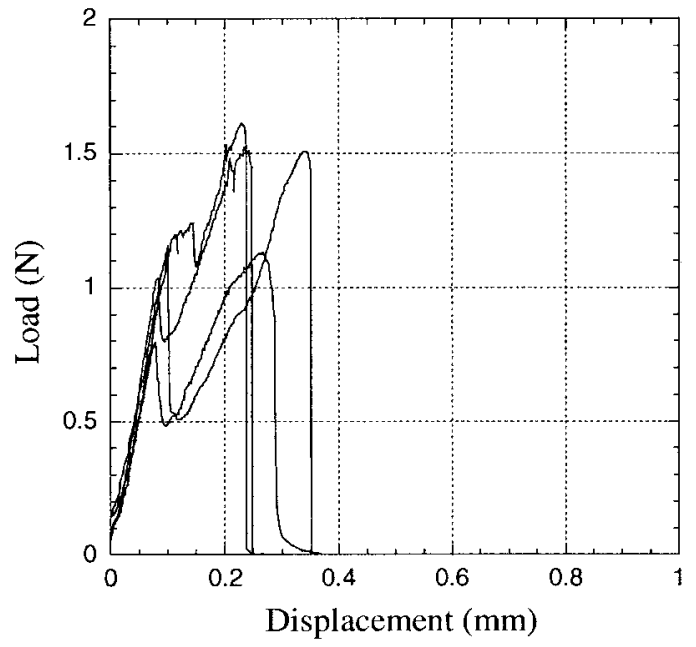

(a)

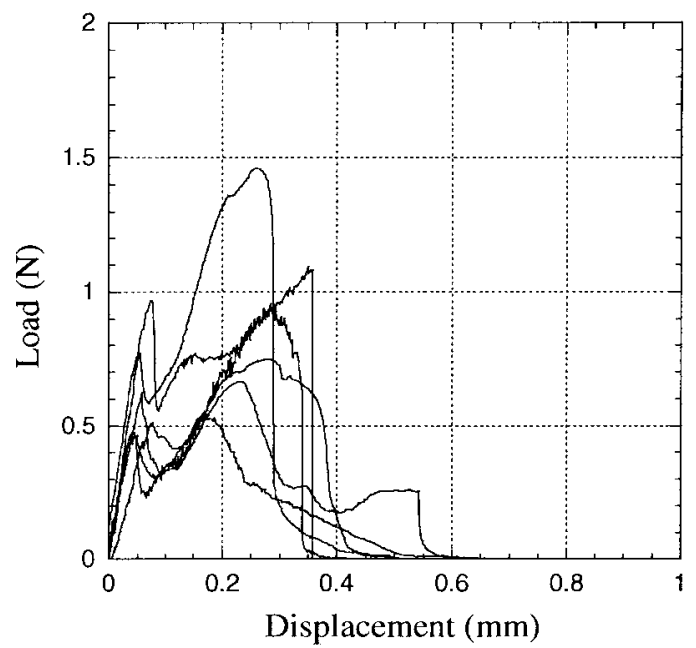

(b)

FIG. 9. Pullout Curves for Fibers A: (a) Nonoiled; (b) Oil Coated

characteristics, it is also logical to measure about $5 \mathrm{~J} / \mathrm{m}^{2}$ for Fiber B and lower ones, about $4 \mathrm{~J} / \mathrm{m}^{2}$, for Fiber A.

The beneficial effects the oiling agent has are quite obvious. A decrease of more than $30 \%$ is achieved in terms of $\tau_{0}$ and $G_{d}$ values for both A and B fibers. The $\beta$ values are also drastically reduced in case of large Fiber $B$, but remain surprisingly unchanged in the case of small Fiber A. 


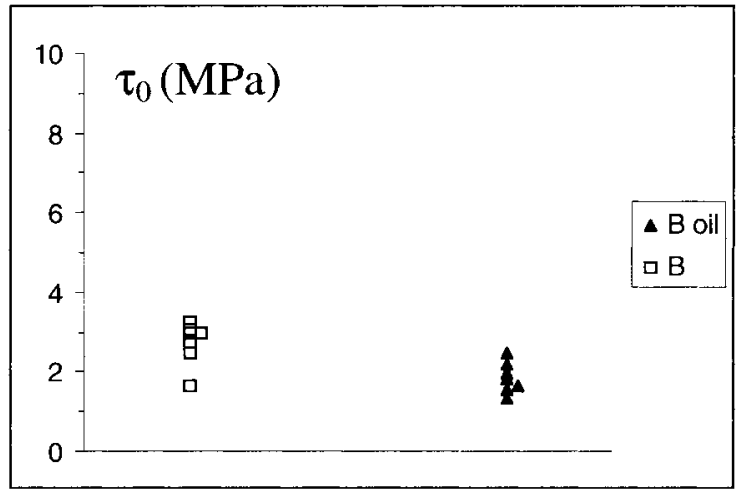

(a)

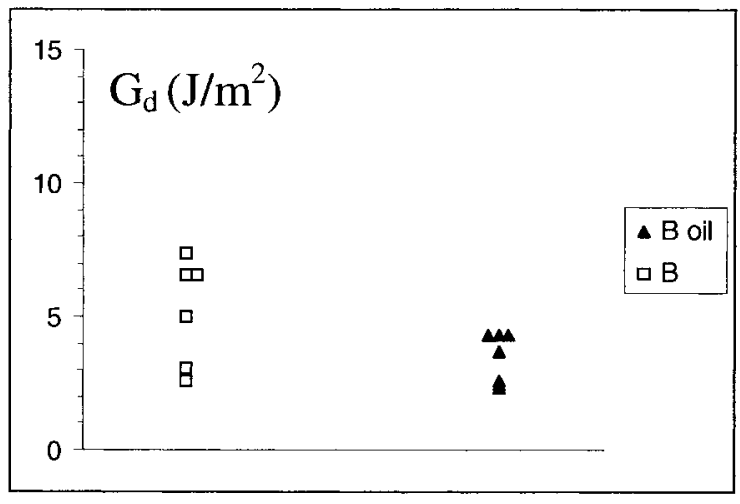

(b)

FIG. 10. (a) $\tau_{0}$; (b) $G_{d}$ Values for Oiled and Nonoiled Fibers B in the ECC Matrix for a Constant $l_{e}=5 \mathrm{~mm}$

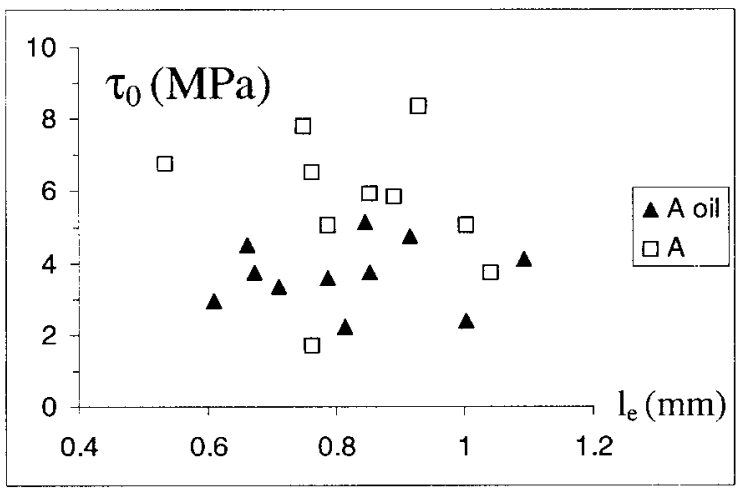

(a)

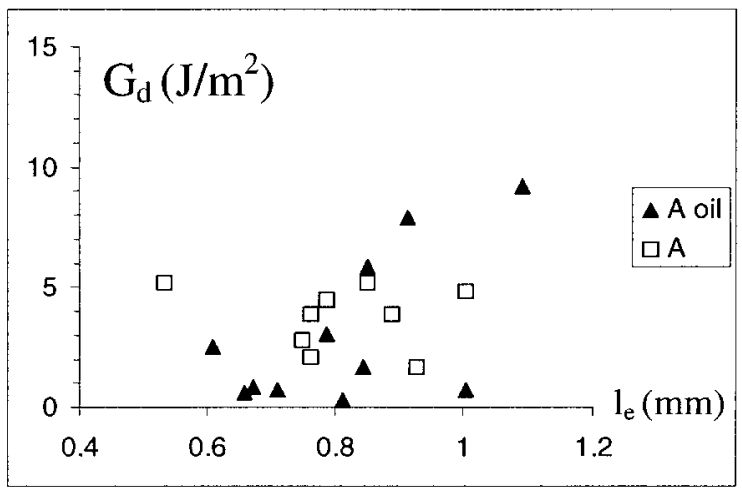

(b)

FIG. 11. (a) $\tau_{0}$; (b) $G_{d}$ Values for Oiled and Nonoiled Fibers A in the ECC Matrix Versus $l_{e}$
TABLE 2. Average Measured Values of $\tau_{0}, G_{d}$, and $\beta$ for the Oil-Coated or Nonoiled PVA Fiber/ECC Matrix Interface

\begin{tabular}{|c|c|c|c|c|c|c|}
\hline $\begin{array}{l}\text { Fiber } \\
\text { type }\end{array}$ & $\begin{array}{c}\tau_{0} \\
\text { (nonoil) } \\
(\mathrm{MPa})\end{array}$ & $\begin{array}{c}\tau_{0} \\
(\mathrm{oil}) \\
(\mathrm{MPa})\end{array}$ & $\begin{array}{c}G_{d} \\
\text { (nonoil) } \\
\left(\mathrm{J} / \mathrm{m}^{2}\right)\end{array}$ & $\begin{array}{c}G_{d} \\
\text { (oil) } \\
\left(\mathrm{J} / \mathrm{m}^{2}\right)\end{array}$ & $\begin{array}{c}\beta \\
\text { (nonoil) }\end{array}$ & $\begin{array}{c}\beta \\
\text { (oil) } \\
\end{array}$ \\
\hline $\mathrm{A}$ & $5.9^{\mathrm{a}}$ & $3.8^{\mathrm{a}}$ & $4.2^{\mathrm{b}}$ & $2.8^{\mathrm{b}}$ & $0.40^{\mathrm{d}}$ & $\overline{0.56^{\mathrm{d}}}$ \\
\hline B & $2.7^{\mathrm{b}}$ & $1.8^{\mathrm{b}}$ & $5^{\mathrm{c}}$ & $3.5^{\mathrm{c}}$ & $2.5^{\mathrm{e}}$ & $0.14^{\mathrm{e}}$ \\
\hline \multicolumn{7}{|c|}{$\begin{array}{l}{ }^{\mathrm{a}} \text { Lowered by } 35 \% . \\
{ }^{\mathrm{b}} \text { Lowered by } 33 \% . \\
{ }^{\mathrm{c}} \text { Lowered by } 30 \% . \\
{ }^{\mathrm{d}} \text { No decrease. } \\
{ }^{\mathrm{e}} \text { Strong decrease. }\end{array}$} \\
\hline
\end{tabular}

\section{CONCLUSIONS AND FURTHER DISCUSSIONS}

The measurements of interfacial bond properties of hydrophilic PVA fibers in the ECC matrix have shown that the chemical bond in PVA/mortar is strong with $G_{d}$ values in the range of 4 to $5 \mathrm{~J} / \mathrm{m}^{2}$. But even though the fiber/matrix chemical debonding occurs, as illustrated by the observed fiber slippage in the fiber tunnel, it does not lead to the fiber rupture. Similarly, although the values of $\tau_{0}$ around 3 (Fiber B) to 5 (Fiber A) $\mathrm{MPa}$ are high, as compared to those of other polymeric fibers - 0.5 MPa for PE and 0.1-0.3 MPa for PP (Lin and Li 1997; Kanda and Li 1998), the initial frictional bond strength does not cause any fiber rupture in these pullout specimens. In fact, the more damaging fiber/matrix bonding occurs during the slip-hardening regime. The values of the slip-hardening coefficient $\beta$, around 0.5 for Fibers A and 2.5 for Fibers B, are two orders of magnitude higher than those obtained for PE fibers, around 0.0125 (Lin and $\mathrm{Li}$ 1997). The observed important abrasion of the fiber surface during fiber slippage in the fiber tunnel graphically illustrates the intensity of the sliphardening effect. The slip-hardening effect might be so strong that stresses generated in the PVA fiber can exceed its apparent tensile strength and prevent the full fiber debonding even for embedment lengths as low as $0.8 \mathrm{~mm}$ (for Fiber A).

An attempt was made to lower these bond values to minimize rupture in a composite, which exhibits pseudo strain hardening. An oiling agent was used to coat the fibers to make them more hydrophobic and to allow them to slip-out more easily. It was partially successful in the sense that the $\tau_{0}$ values were decreased by $33-35 \%$ in the 2 (Fiber B) to 4 (Fiber A) MPa range. The $G_{d}$ values were also lowered by $30-33 \%$ in the range of 3 to $3.5 \mathrm{~J} / \mathrm{m}^{2}$. However, if the oil coating was successful in diminishing the slip-hardening effects on the large Fibers B, it failed to do so for the small Fiber A.

Two outstanding issues remain to be resolved. First, the influence of the coating agent on the slip-hardening effect appears very different between the two, Fibers A and B. Whether this can be traced back to the difference in uniformity of coating along the length of the two fibers is not clear. SEM studies show no distinctive variations. The second issue is linked to the notion of apparent fiber tensile strength, which is exceeded in the case of the small fibers and not for the large fibers. It is not desirable to exceed it during the slip-hardening regime if full fiber debonding has to be ensured to get a composite as ductile as possible. It is necessary to understand how and why the abrasion process would damage only a peripheral PVA material thickness on the large fibers to avoid delamination through the whole thickness of the small diameter fibers.

In broad conclusions, this study confirms that even in the case of fibers rupturing during the pullout process, it is possible to determine interfacial bond properties as long as full fiber debonding can be independently verified, as shown in Fig. 5. This study also indicates that it is important to incorporate slip-dependent frictional stress to model the effects of fiber breakage in the composite due to interface slip-hardening. 
Finally, it was demonstrated that within certain restrictions, lowering the interfacial bond values can be achieved using an oil coating. This would be desirable to develop PVA-ECC composites with improved ductility.

\section{ACKNOWLEDGMENTS}

This research has been supported by a grant to the ACE-MRL at the University of Michigan from the Kuraray Co., Ltd., Osaka, Japan.

\section{REFERENCES}

Cooper, G. A., and Kelly, A. (1970). "The contribution to the work of fracture of a composite material of pull-out fibers." Mechanics of composite materials, F. W. Wendt, H. Liebowitz, and N. Perrone, eds., Pergamon, Oxford, U.K., 653-661.

Gao, Y. C. (1987). "Debonding along the interface of composites." Mech. Res. Communications, 14(2), 67-72.

Huseh, C. H. (1990). "Evaluation of interfacial shear strength, residual clamping stress and coefficient of friction for fiber-reinforced ceramic composites." Acta Metall., 38(3), 403-409.

Kanda, T., and Li, V. C. (1998). "Interface property and apparent strength of high-strength hydrophilic fiber in cement matrix." J. Mat. in Civ. Engrg., ASCE, 10(1), 5-13.

Katz, A., and Li, V. C. (1996). "A special technique for determining the bond strength of microfibers in cement matrix by pull-out test." J. Mat. Sci. Letter, 15, 1821-1823.

Leung, C. K. Y., and Li, V. C. (1990). "Strength-based and fracture based approaches in the analysis of fibre debonding." J. Mat. Sci. Letter, 9, $1140-1142$.

Li, V. C., et al. (1996a). "Micromechanical models of mechanical response of HPFRCC," A. E. Naaman, and H. W. Reinhardt, eds., RILEM Proc. 31, E\&FN Spon, London, 43-100.

Li, V. C., and Stang, H. (1997). "Interface property characterization and strengthening mechanisms in fiber reinforced cement based composites." J. Advanced Cement Based Mat., 6(1), 1-20.

Li, V. C., and Wu, H. C. (1992). "Conditions for pseudo strain hardening in fiber reinforced brittle matrix composites." Appl. Mech. Rev., 45, 390-398.

Li, V. C., Kanda, T., and Lin, Z. (1997). "The influence of fiber/matrix interface properties on complementary energy and composite damage tolerance." Proc., 3rd Conf. on Fracture and Strength of Solids, 145149, Hong Kong, 456-472.
Li, V. C., Mishra, D. K., and Wu, H. C. (1995). "Matrix design for pseudo-strain-hardening fiber reinforced cementitious composites." $J$. Mat. and Struct., 79(183), 586-595.

Li, V. C., Wu, H. C., and Chan, Y. W. (1996b). "Effect of plasma treatment of polyethylene fibers on interface and cementitious composite properties." J. Am. Ceramic Soc., 79(3), 700-704.

Lin, Z., and Li, V. C. (1997). "Crack bridging in fiber reinforced cementitious composites with slip-hardening interfaces." J. Mech. Phys. Solids, 45(5), 763-787.

Lin, Z., Kanda, T., and Li, V. C. (1999). "On interface property characterization and performance of fiber-reinforced cementitious composites." J. Concrete Sci. and Engrg., 173-184.

Marshall, D. B., and Cox, B. N. (1988). "A J-integral method for calculating steady state matrix cracking stresses in composites." Mech. of Mat., 7, 127-133.

Naaman, A. E., and Reinhardt, H. W., eds. (1996). "High performance fiber reinforced cementitious composites." RILEM Proc. 31, E\&FN Spon, London.

Stang, H., Li, Z., and Shah, S. P. (1990). "Pullout problem: Stress versus fracture mechanical approach." J. Engrg. Mech., ASCE, 116(10), 2136-2150.

Wu, H. C., and Li, V. C. (1997). "Basic interfacial characteristics of polyethylene fiber/cement composites and its modification by plasma." Proc., 5th Int. Symp. on Brittle Matrix Compos. (BMC-5), Warsaw, Poland, 14-23.

\section{NOTATION}

The following symbols are used in this paper:

$d_{f}=$ fiber diameter;

$E_{f}=$ elastic modulus of fiber;

$G_{d}=$ chemical debonding energy;

$l_{d}=$ fiber debond length;

$l_{e}=$ fiber embedment length;

$P=$ pullout load in single fiber pullout curve;

$P_{a}=$ peak load of single fiber pullout curve;

$P_{b}=$ load after sudden drop following $P_{a}$;

$S$ = slippage distance;

$\beta=$ slip-hardening coefficient; and

$\tau_{0}=$ initial frictional bond strength. 